\title{
UNA EXPERIENCIA DE FORMACIÓN EN TIC DESDE LA PERSPECTIVA DE GÉNERO
}

\author{
TRAINING EXPERIENCE IN ICT FROM A GENDER PERSPECTIVE
}

Annachiara Del Prete ${ }^{1}$

\section{RESUMEN}

El presente artículo está basado en el proyecto: "Las TIC como herramienta de empoderamiento para el colectivo de mujeres mayores", que ha consistido en una serie de talleres sobre habilidades básicas informáticas, dirigidos a un colectivo de mujeres cuyas edades son comprendidas entre 50 y 70 años, del Municipio de Pamplona (Norte de Santander Colombia). Utilizando el paradigma metodológico cualitativo lo que se pretendido ha sido capacitar a las mujeres mayores participantes al proyecto en el uso de las TIC como herramienta de empoderamiento y de construcción del conocimiento a través del recupero de la memoria. Los resultados obtenidos han sido un cambio de discurso significativo con respecto al auto-concepto de sí mismas y la edición de un documento en formato digital y en papel que recompila y rescata la historia de las mujeres del municipio y su participación al desarrollo económico y cultural del municipio.

\section{Palabras clave}

género, educación, TIC, empoderamiento, aprendizaje a lo largo de la vida

\section{ABSTRACT}

This article is based on the project: "ICT as a tool of empowerment for the group of older women", that has consisted of a series of workshops on basic computer skills targeted to a group of women whose ages are between 50 and 70 years, of the Municipality of Pamplona (Norte de Santander Colombia). By using a qualitative methodological paradigm we intended to train older women participating in the project of using ICT as a tool of empowerment and knowledge construction through the recovery of memory. The results have been a significant change of discourse regarding the self-concept of them and editing a document in digital and paper format that recompiles and saves the history of women in the municipality and its participation in economic and cultural development of the municipality.

\section{Keywords}

Gender, education, ICT, empowerment, lifelong learning

\section{A ANÁlisis DEL CONTEXTO DE ESTUDIO}

Aunque es innegable que en los últimos años la sociedad colombiana ha sido protagonista de significativos cambios $y$ avances en muchos sectores de la sociedad, la crisis económica y social, resultante de la generalización de las políticas neoliberales (apertura económica, ajuste fiscal, reducción de la función económica y social del Estado, flexibilización laboral) que se manifestó hacia

\footnotetext{
Licenciada en Literatura Moderna con especialidad en Historia Contemporánea. Doctora en Tecnología Educativa. Máster Europeo en "Políticas locales, género y desarrollo". Máster en Comunicación y Tecnología Multimedia. Profesora Titular por la facultad de Educación de la Universidad Autónoma de Santiago (Chile). Ha realizado diversas investigaciones.
} 
finales de la década de los noventa, ha llevado a un incremento de la pobreza y el hambre, el desempleo y el subempleo, la privatización de los servicios sociales básicos y el cada vez más difícil acceso a ellos, por parte de la mayoría de la población, sin olvidar la persistencia y agudización del conflicto armado, que ha incidido gravemente en su sociedad. En este contexto social y político la situación de las mujeres se ha visto notoriamente afectada como consecuencia del deterioro en la prestación y el acceso a los servicios sociales básicos y del aumento del desempleo $y$ el subempleo. Igualmente, el incremento del desplazamiento forzado interno y hacia los países vecinos, ha afectado de manera especial a las mujeres (Ahumada 2008).

De hecho, Colombia se caracteriza por una gran brecha entre la normatividad jurídica y la realidad social y política. Existe un amplio reconocimiento de los derechos de las mujeres, pero enormes dificultades para realizarlos (Meertens 2007). Esta situación hace más difícil visibilizar la discriminación y las violencias que se ejercen contra ellas $y$, por ende, dificulta también la puesta en marcha de acciones contundentes que resulten en una reducción de las desigualdades existentes entre los géneros.

En tal contexto el compromiso más difícil de asumir parece ser el de incidir en las realidades que se caracterizan por padecer discriminaciones no sólo de género, sino a todos los niveles como el educativo, el económico y de salud, siendo ésta la realidad de las mujeres y de un amplio sector de la sociedad colombiana.

Desde la práctica educativa la propuesta es trabajar por el empoderamiento de las mujeres para que de esta manera, ellas mismas sean las artífices del cambio de su realidad, que ellas mismas establezcan las prioridades que se deben tener en cuenta a la hora de diseñar acciones dirigidas a mejorar sus condiciones en la sociedad colombiana.

Nos referimos a las mismas mujeres que sufren las consecuencias de una desigual distribución de recursos, de la falta de educación, que llenan los cupos del trabajo informal, sector que tiende a convertirse en permanente o de largo plazo, para una proporción cada vez más importante de quienes recurren a él, que sufren la dificultad de acceso a los servicios de salud, y a un asesoramiento para los derechos sexuales y reproductivos, lo que contribuye al incremento del embarazo en edad adolescente. ${ }^{2}$ Son las mismas mujeres que, en gran número, resultan ser víctimas de violencia intrafamiliar. ${ }^{3}$

Parte de las condiciones antes descriptas, forma parte de la realidad de las mujeres de las asociaciones del municipio Pamplona, Norte de Santander ${ }^{4}$ y por esto nuestra atención ha sido dirigida a ellas, con el fin de diseñar una acción pedagógica que a través de la transmisión de las habilidades digitales, tenga como objetivo empoderarlas. Se ha intentado, de esta manera incidir en su cultura que lleva en sí las marcas patriarcales, a través de un trabajo de sensibilización y concientización para que las mismas mujeres se vuelvan dueñas de sus propias vidas y puedan librarse de los estereotipos y creencias que las tienen prisioneras de sus destinos.

\section{B LAS TIC EN COLOMBIA}

La denominada "Sociedad del Conocimiento" presenta grandes desafíos a cualquier país en la actualidad, pero en los países en desarrollo

\footnotetext{
Según la Encuesta Nacional de Demografía y Salud de Profamilia (ENDS) en 2010 se logró detener la tendencia creciente que presentaba el embarazo en la adolescencia entre el 1990 y 2005; sin embargo, la cifra aún continúa siendo alta; para el año 2010 una de cada cinco mujeres de 15 a 19 años, está o ha estado alguna vez embarazada; el 16\% ya son madres y el $4 \%$ está esperando su primer hijo. No es coincidencia que, así como afirma ENDS, el mayor porcentaje de madres adolescentes se sitúa en niveles de educación bajos. EL 55\% de adolescentes que han sido madres no tiene ningún nive de educación; el $46 \%$ apenas tienen primaria, frente a menores porcentajes cuando el nivel educativo es mayor como en secundaria $18 \%$ y educación superior $11 \%$ (ENDS 2010).

3 Según Medicina Legal, durante el año 2011 se registraron 57.761 casos de violencia de pareja, de los cuales el 88\% de las víctimas fueron mujeres. Durante el año 2012, los casos llegaron a 46.819 con un porcentaje de $87 \%$ para las mujeres.

4 Pamplona es un municipio del departamento del Norte de Santander, su área territorial es de $318 \mathrm{Km} 2$. El área urbana
} 
los retos son mayores ya que hay muchos obstáculos superados, aunque no del todo, por las naciones más desarrolladas (pobreza, desigualdades sociales, bajos índices de educación, pocas oportunidades de salud, trabajo y vivienda), que aún son tarea pendiente por resolver.

En la actualidad, Colombia observa serias disparidades en lo que a acceso a las tecnologías de la información y comunicación se refiere. De hecho si miramos los datos presentados en la publicación más reciente en materia de TIC, que es el índice de preparación tec $\neg$ nológica del Networked Readiness Index o NRI,) del World Economic Forum (WEF), se observa como la penetración de las TIC en Colombia es todavía baja, con solo un poco más de $20 \%$ de hogares con servicio de conexión a Internet. Datos de la Gran Encuesta Integrada de Hogares (GEIH) de 2011 indican que tan sólo el 23,4\% de los hogares cuenta con conexión al servicio de internet, con una alarmante brecha entre cabeceras $(29,5 \%)$ y el resto del país $(2,4 \%)$. La baja y desigual penetración que se observa en la conexión a internet está asociada a la escasa disponibilidad de redes en las zonas alejadas del país y al bajo porcentaje $(29,8 \%)$ de hogares colombianos que cuentan con un computador. (Informe Nacional de Competitividad 2012-2013)

Este indicador, junto a varios descriptos en la misma publicación, denuncia que Colombia regis-tró en 2012 una caída de 15 puestos con relación a 2011, y se ubicó en el puesto 73 entre 144 países. Esta caída dejó en evidencia las falencias que tiene Colombia en materia de TIC. La concentración de la riqueza y la distribución de la misma se configuran como hechos estructurales que explican de forma complementaria la baja penetración de las TIC en el país. La relación entre ingresos y el uso de las TIC es comprobada a partir del análisis estadístico de variables. Se encuentra que a mayores ingresos el acceso aumenta (Ramírez et al. 2008).

En materia de educación, el analfabetismo, en lo que refiere al uso adecuado de las TIC y la falta de competencias del capital humano, es un factor determinante del éxito en la masificación de estas tecnologías. Según la Encuesta Nacional de Alfabetización Digital de 2009 realizada por ICDL Colombia ${ }^{5}$, el Sena y el Ministerio de TIC, solo $45 \%$ de los encuestados resultó clasificado como "Alfabetizado digital", mientras que el $47 \%$ mostró tener "Habilidades básicas" para utilizar la tecnología digital y el $7 \%$ con "Habilidades insuficientes". El promedio de Alfabetizados digitales de Europa y Asia, por el contrario, alcanza el 62\%.(Informe Nacional de Competitividad 2012-2013)

En lo que concierne a las TIC y Género, las iniciativas encontradas son escasas; la mayoría ofrece asistencia social y formación en trabajos tradicionales a mujeres carenciadas. Muy pocas de ellas relacionan la necesidad de trabajar con la de incorporarse con nuevas armas y herramientas a un mercado laboral en evolución. En Colombia, el ITSA (Instituto Tecnológico de Soledad, Atlántico ${ }^{6}$ ), desarrolla el Programa Madres en $\mathrm{Red}^{7}$ cuyo objetivo es proveer capacitación en TIC a mujeres, madres de familia, víctimas de la violencia, provenientes del conflicto armado que afecta a la región.

En general los programas detectados dirigidos a la promoción y difusión del uso de TIC no toman en cuenta los aspectos de género: muy pocos se dirigen a la formación de mujeres en herramientas de TIC, ni a su empleabilidad en trabajos que impliquen el uso de estas

de la ciudad ha sido catalogada como capital o centro principal de la provincia Sur-occidental del departamento; durante las últimas décadas el proceso de urbanización ha ido incorporando zonas rurales al área urbana. En las zonas rurales los ingresos medios son inferiores a los que prevalecen en el área urbana En los últimos años la situación, en lugar de mejorar, ha empeorado especialmente en lo referente a la baja productividad y a los escasos beneficios del trabajo del campesino y la campesina, a lo que se le añade la inaccesibilidad a los servicios sociales, los bajos indicadores en salud, las altas tasas de analfabetismo y escolaridad incompleta.

5 ICDL Colombia, entidad sin ánimo de lucro, representante exclusiva de la Fundación ECDL con sede en Irlanda y que gestiona la iniciativa Ciudadano Digital.

6 http://www.itsa.edu.co

7 http://www.agenda.gov.co/articulos/181/ 
tecnologías. En estos programas y planes, ni siquiera se han encontrado referencias al acceso y formación en TIC inequitativos entre los sexos, a pesar de claras diferencias de género identificadas en el país. Rara vez incorporan componentes en TIC favorables a las mujeres ni examinan la forma en que sus componentes beneficiarán a las mujeres pobres (Finquelievich et al. 2004).

\section{La formación en TIC como estrategia de empoderamiento}

Nuestro compromiso para impulsar la creación de nuevo conocimiento, para llevar a cabo la investigación desde la perspectiva de género y utilización de nuevos enfoques y apoyo a iniciativas innovadoras, ha dirigido nuestra acción a fomentar el empoderamiento de las mujeres utilizando la tecnología de la información y comunicación como herramienta innovadora para este logro.

Las TIC pueden contribuir a la mejora de la condición de las mujeres en varios sectores, como combatir la pobreza con nuevas oportunidades de empleo y de comercialización de los productos; o a través de la formación e información, combatir la violencia de género, mediante la transmisión del conocimiento. Nuestra propuesta de intervención para el empoderamiento del colectivo de mujeres de las asociaciones sociales del municipio de Pamplona se basa en un curso en alfabetización digital y la recuperación de la memoria histórica.

Esta propuesta parte de una reflexión que nos lleva a considerar necesario empezar un trabajo de recuperación de la memoria, un rescate de las historias de vida de cada mujer. A través de la concientización sobre los abusos que, sea en las relaciones privadas, sea en el contexto social, muchas mujeres han sufrido y siguen padeciendo, se les anima a que cuenten sus historias de vida para que se transmitan en testimonio y evitar que sigan perpetuándose los malos tratos. El trabajo de escritura y de relectura de sus propias experiencias desde un enfoque de género puede favorecer la concientización, un nuevo posicionamiento frente a sus realidades $y$ puede estimular una nueva actitud frente a las dificultades.

Creemos fuertemente en la importancia del rescate de las experiencias positivas de las mujeres, para que no se creen ni se transmitan modelos exclusivos de víctimas, pero también es necesario denunciar realidades de mujeres que sí fueron víctimas de las culturas y de los hombres, víctimas especialmente de la cultura patriarcal.

\section{¿Por qué las tecnologías de la información y de la comunicación como herramienta de empoderamiento?}

El empoderamiento de la mujer, en relación a las tecnologías de la información y la comunicación, implica la mejora de las habilidades, conocimiento, acceso y uso de las TIC. En esta definición se incluye un objetivo estratégico referido al incremento de la participación y el acceso de la mujer a la expresión y a la toma de decisiones en y mediante los medios y las tecnologías de la información y de la comunicación.

La relación de ambos conceptos -TIC y empoderamiento- se entiende desde una doble perspectiva, así como lo señalan Gemma Aguado, Anna Escofet y María José Rubio (2009):

\section{a. Las TIC como vehículo de} empoderamiento social. La idea que subyace bajo esta perspectiva es que las TIC pueden ser un importante catalizador para el empoderamiento político y social de la mujer y para la promoción de la equidad de género. Existe un reconocimiento del potencial de las tecnologías como vehículo para lograr o mejorar la igualdad de género. Así, por ejemplo, el uso y la competencia de herramientas promueve las posibilidades de empleo y autoempleo; o la participación en comunidades y redes virtuales puede aumentar la capacidad de la libre expresión y de la toma de decisiones a diferentes niveles de la vida de las mujeres. 
b. El empoderamiento con las TIC. Esta perspectiva hace referencia al nivel de acceso, uso, competencia y actitud frente a las TIC.

En resumen, el empoderamiento de la mujer se centra en el incremento de su poder en las decisiones claves de su vida, incluidas las relacionadas con el acceso a los recursos, la participación en la toma de decisiones y en la distribución de los beneficios. Se trata de un proceso más que de una estrategia, por lo que no puede haber agencias de desarrollo para empoderar a las mujeres, sino que han de ser ellas quienes se empoderen a sí mismas. El concepto enfatiza la idea de la mujer como agente activo. Así pues, la autonomía, el dominio, el control, la toma de decisiones y la libertad para elegir son aspectos imprescindibles en el estudio del empoderamiento (Aguado et all 2009).

En el contexto de nuestro ámbito de estudio, creemos que el reinterpretar la historia de vida bajo la perspectiva de género, el superar las barreras que se crean entre las mujeres y las máquinas, puede ser el comienzo para un proceso eficaz de Empoderamiento. En cuanto estas barreras son consecuencias de la poca formación y de los estereotipos culturales, tradiciones, normas e instituciones que imponen relaciones de género que todavía permanecen en nuestra sociedad y que no fortalecen a las mujeres, sino que las subordinan y discriminan también en el campo de la tecnología.

Desde la perspectiva de género las demandas feministas coinciden en la necesidad de formar a las mujeres y sus organizaciones en el uso estratégico de las TIC promoviendo cursos que cubran un amplio abanico de temáticas y, a la vez, el empoderamiento que es fundamental para el logro de la igualdad, el desarrollo y la paz. Es necesario intentar que las mujeres sean beneficiarias de los procesos, que participen en las capacitaciones.

Tradicionalmente se consideran a las mujeres como tecnófobas, de tener una actitud un poco pasiva $e$ incluso temerosa hacia la tecnología (y la red va incluida en el paquete).
Y de hecho, existen unas barreras (reales o subliminales) que a menudo inhiben o dificultan el acceso y el uso por parte de las mujeres a estas nuevas tecnologías. Este hecho se refleja en un bajo porcentaje de utilización, en comparación con los hombres. Aunque hoy en día las estadísticas afirman que con respecto al acceso, la brecha digital de género está prácticamente desapareciendo en los países desarrollados, en América latina y en el Caribe esta brecha sigue existiendo y a ésta se le añade una enorme diferencia en el uso que hombres y mujeres hacen de las TIC (Bonder 2007). A menudo esta idea ha sido utilizada para "justificar" la baja presencia de las mujeres en el diseño, producción y uso de estas, idea que hace invisible la gran contribución que las mujeres han aportado y aportan al desarrollo de las TIC, así como sus diferentes perfiles, lo que silencia sus necesidades como usuarias, necesidades que se habrían que tener más en cuenta a la hora de diseñar contenidos.

\section{Metodología}

Para el desarrollo de este proceso formativo se ha elegido utilizar la metodología de investigación acción participativa feminista IAPF

Para definir la opción metodológica se han tenido en cuenta los siguientes supuestos. 1) El compromiso para el cambio social: la intención explícita de que la investigación sea parte de un proceso para el cambio social y la no discriminación.2) La valoración y el respeto a todas las subjetividades que están implicadas, explícita o implícitamente, en el proceso de investigación. 3) El desarrollo de procesos de reflexión crítica que es imprescindible para cualquier proceso de investigación. Consiste en poner constantemente en duda lo que estamos haciendo y problematizarlo, para evidenciar sus características y limitaciones. Práctica esta, fundamental para favorecer procesos abiertos al cambio.

Como objetivos que se pretenden alcanzar con la investigación-acción participativa feminista se destaca, por una parte, producir conocimiento y acciones útiles para un grupo de 
personas; por otra, que la gente se empodere/ capacite a través del proceso de construcción y utilización de su propio conocimiento.

El empoderamiento y la capacitación se dan gracias a la participación activa $y$ protagónica de todas las integrantes del grupo -incluyendo la investigadora- en el proceso investigativo y de enseñanzaaprendizaje, que se genera a través de la acción pedagógica.

Para facilitar esta participación activa de todas las implicadas en el proceso y la emergencia de la pluralidad de saberes presentes en el grupo, se utilizan técnicas dinamizadoras que ayudan a la consecución de dichos objetivos metodológicos y otros objetivos específicos.

Otra ventaja inherente a la metodología investigación-acción participativa feminista es el fortalecimiento de las capacidades creadoras y críticas en las participantes, quienes aprehenden su realidad y encuentran nuevas respuestas a los dilemas que esta les propone día a día. En este sentido se busca que las participantes resinifiquen su experiencia y la de las demás, con lo que su aprendizaje se contextualiza en su realidad cotidiana y se ajusta a las particularidades de su proceso de desarrollo.

\section{Objetivos del proceso formativo}

\section{Objetivo general}

Capacitar a las mujeres de las asociaciones del Municipio de Pamplona en el uso de las TIC, como herramienta de empoderamiento en relación a la percepción de sí mismas y para la recuperación de su memoria histórica.

\section{Objetivos específicos.}

- Favorecer la adquisición de habilidades básicas en el uso de las tecnologías de la información y comunicación.

- Crearespaciosde debatey de intercambio de ideas, críticas, interpretaciones, etc., entre el grupo de mujeres participantes sobre la evolución de su papel en la sociedad y las desigualdades de género existentes.

- Elaborar a través del apoyo de las tecnologías de la información y la comunicación, dossieres personales que recojan, a través de imágenes y textos, las temáticas tratadas a lo largo de los talleres.

- Editar un documento impreso, que recoja todas las experiencias de las mujeres participantes en el taller.

Han sido las mismas participantes al taller quienes han propuesto los contenidos a tratar durante el aprendizaje del manejo del computador, para que se sintieran cómodas y motivadas. De este modo se han tenido en cuenta las características de la metodología participativa que, como recordamos, prevé que la problemática a tratar interese a la propia comunidad o lugar de trabajo y que sea central el papel que se asigna a fortalecer la toma de conciencia en la gente sobre sus propias habilidades, recursos y necesidades, como es el caso que se ha tratado en esa sede.

La temática elegida ha sido: la recuperación de la memoria histórica.

Las participantes en los talleres han sido un total de 31 mujeres de una edad media de 55 años. La mayoría es desempleada y recibe una ayuda social muy baja o empleada en pequeñas empresas locales. De las 31 mujeres participantes a los talleres, 16 cursaron los estudios primarios, 4 estudios secundarios y 11 llegaron al bachillerato. La totalidad de las mujeres desarrolla el trabajo doméstico y de cuidado de familiares descendientes y ascendientes, sin ayuda de parte del cónyuge. De 31 mujeres, 20 son cabeza de familia, el marido las abandonó junto a su prole. De la totalidad de las participantes en el curso, el $85 \%$ admite haber sido víctima de violencia de género por lo menos una vez en la vida.

\section{Recolección de datos}

Para la recolección de los datos, que nos han servido para conocer las beneficiarias del proceso formativo y adaptar, de tal manera, el diseño pedagógico a sus necesidades 
especificas y para obtener datos con el fin de evaluar el desarrollo del proceso se han utilizado diferentes instrumentos.

En primer lugar se ha elaborado un cuestionario sobre datos personales y sobre alfabetización digital para caracterizar las usuarias de los talleres y adaptar a sus necesidades la logística y la metodología del proceso formativo.

Un segundo instrumento, fundamental a la hora de identificar las necesidades específicas de las mujeres, han sido los grupos de discusión. El desarrollo de estos ha permitido sentar la base del proceso de cambio en la percepción que cada mujer tiene de sí misma y del rol que desarrolla en la sociedad y para, de tal manera, empezar el proceso de empoderamiento. Mediante un diálogo crítico y constructivo se han interpelado los modelos de desarrollo que habían primado en la sociedad y que de una u otra manera habían invisibilizado a las mujeres. Se han introducido conceptos como patriarcado, género, derechos de las mujeres y discriminación. De allí se ha dado inicio a una fase de concientización de los roles asumidos, impuestos y trasmitidos.

Otro instrumento de recolección de datos ha sido la Entrevista semidirigida. Las entrevistas han sido realizadas en el mismo entorno donde las mujeres desarrollan su vida cotidiana $y$ esto ha ayudado a generar confianza y comodidad. La entrevista semidirigida se ha centrado en recoger las manifestaciones de las mujeres que han participado en los talleres en torno a un guión general flexible que ha sido construido a partir de las preguntas de evaluación (la guía de entrevista). La entrevista semidirigida es la forma más empleada en evaluación y en nuestro caso nos ha servido para cruzar la información obtenida durante los grupos de discusión y finalmente recoger los resultados de nuestros talleres. Las entrevistas han sido dirigidas a algunas de las mujeres que han participado en los talleres, según el criterio del muestreo de sujeto-tipo que consideramos apropiado y se han realizado de forma presencial. Se ha utilizado la videocámara para la grabación, después de pedir la autorización a las entrevistadas para poderlas filmar.
Una última técnica utilizada para alcanzar nuestro objetivo de Empoderar a las mujeres ha sido la redacción de historias de vida por parte de las participantes en los talleres. Esto nos ha servido para que la mujeres recorrieran sus experiencias a la luz de nuevos conceptos tales como, dignidad, igualdad de oportunidades, opresión patriarcal, roles de género, y al mismo tiempo recuperaran la memoria de sus vivencias y de sus experiencias. En estas historias se ha podido observar la percepción de cada una respecto a su propia experiencia de vida, recolección de testimonios y recuerdos.

Por lo que respecta a la adquisición de las habilidades informáticas se ha recorrido a la observación directa de los avances, límites y obstáculos encontrados por las mujeres respecto al aprendizaje en el uso básico de las TIC y a través de la realización de un diario de campo se ha podido sistematizar el proceso pedagógico.

Cada taller ha sido grabado con una videocámara, después de haber pedido autorización a las mujeres para el uso del material grabado.

\section{El desarrollo de una experiencia de formación en TIC desde la perspectiva de género}

La población beneficiaria del proceso educativo propuesto han sido las asociaciones de mujeres del Municipio de Pamplona (norte de Santander) que han querido participar a los Talleres de Alfabetización digital, con el fin de adquirir capacidades en el uso de las TIC, como herramienta de empoderamiento en relación a la percepción de sí mismas y para la recuperación de su memoria histórica. La decisión de trabajar con las asociaciones de mujeres se ha tomado en cuanto representantes las de las mujeres del municipio y porque a través de ellas se ha facilitado hacer extensiva la propuesta formativa a un amplio número de mujeres. Inicialmente, el contacto se ha realizado con lideresas de las asociaciones, quienes a su vez socializaron la propuesta entre sus integrantes. 
Lo que ha estimulado a las mujeres de las asociaciones a empezar los talleres ha sido la curiosidad de acercarse a las TIC herramientas que, hasta la fecha, consideraban lejos de su alcance, aunque percibían su importancia, sobre todo debido al gran uso que de estas hacen sus familiares, en particular sus hijos/as y sus nietas/os. En segundo lugar siempre es un estimulo, para estas mujeres, participar en cursos de formación, sobre todo como espacio para compartir y debatir con sus compañeras.

Las asistentes se inscribieron el primer día al taller, pero nos encontramos que durante el transcurso de las sesiones se incorporaron más mujeres, estimuladas por los comentarios de las compañeras que ya participaban. También hubo algún abandono en el grupo, pero por cuestiones familiares, no por la formación del taller en sí.

La propuesta metodológica a emplear ha tenido dos referentes: 1) la investigación participativa, en el que las mujeres son sujetas activas en la investigación y, 2) la perspectiva de género, herramienta teórica que se apoya en una metodología cualitativa, considerando los aspectos de clase, etnia y edad. Esta perspectiva permite hacer visibles a las mujeres, dar valor a la experiencia individual y colectiva y analizar y reflexionar sobre sus relaciones sociales.

El taller ha sido diseñado para tener una duración de 20 horas, repartidas en 5 sesiones de 4 horas. Estas sesiones se han adaptado a la disponibilidad horaria de las mujeres, de los locales y equipamientos.

A continuación pasamos a la descripción de los procesos desarrollados a lo largo de los talleres, con el fin de conseguir los objetivos que se han propuesto alcanzar con la implementación de este proceso educativo.

\section{Los grupos de discusión}

Los grupos de discusión se han llevado a cabo a lo largo de las cinco sesiones en las que se han desarrollado los talleres; los temas que se han tratado han sido varios: la educación, el trabajo, los roles de las mujeres en la familia y en la sociedad, la violencia de género, el acceso a los recursos y la relación con las TIC. Los grupos de discusión han empezado con una aclaración de conceptos. El paso siguiente ha sido el de recoger las observaciones y el testimonio de cada mujer respecto a las temáticas tratadas.

Se ha observado un interés general respecto a los conceptos que para muchas mujeres han resultado nuevos, más por la nomenclatura que por el significado en sí, que tenían bien asumido en su visión de la vida. Nos referimos sobre todo a conceptos como el de violencia de género y sociedad patriarcal, de dominio de una sociedad machista y el control que esta sociedad tiene sobre la vida de las mujeres. Cada mujer se ha mostrado consciente de esta realidad y al mismo tiempo de los cambios que se están presentando en las nuevas generaciones. Muchas se han reconocido víctimas de los estereotipos culturales vigentes en su entorno, pero también alguna ha resaltado la rebeldía valiente que la ha llevado a ser mujer cabeza de familia y a luchar día tras día en una sociedad "dominada por los varones". La coincidencia en los recuerdos y en los testimonios ha llevado a una empatía dentro del grupo que ha generado conmoción a ratos, y fuerza para enfrentar las problemáticas que iban surgiendo en las discusiones.

Destaca una conciencia común sobre la necesidad de solidaridad y unión del colectivo de mujeres para enfrentarse a la discriminación de género, como por ejemplo la discriminación sufrida a la hora de recibir una educación en el contexto de una familia con escasez de recursos, que ha primado los hombres para "recibir estudios", relegando a las mujeres al desarrollo de tareas de cuidado. También se ha encontrado una postura común con respecto a la violencia de género, problemática que se enfrenta a una asistencia estatal ausente y a unas leyes que todavía se quedan en el papel.

Con respecto a la relación con las TIC, la mayoría comparte un analfabetismo tecnológico y una sensación de incapacidad en el manejo del medio. Se reconoce, sin 
embargo, la importancia de uso y acceso a las tecnologías de la información y la comunicación y se denuncia la falta de cursos dirigidos específicamente al colectivo de mujeres de la tercera edad, víctimas de una brecha digital generacional y de una discriminación a la hora de diseñar procesos educativos.

En el trascurso de los grupos de discusión resaltó la necesidad de escribir y compilar los testimonios que iban surgiendo para llevar a cabo el proceso de concienciación, de relectura de sus propias experiencias, de creación del documento histórico que sirva a la trasmisión e impida el olvido.

\section{El aprendizaje de las TIC}

El primer paso para la formación en el manejo básico de las TIC fue la entrega del material didáctico explicativo del funcionamiento del ordenador, como un glosario de terminología y la explicación del uso de las teclas del ordenador. Se hizo una introducción a la terminología y a los conceptos clave respecto al proceso: el uso de un ordenador, sistema operativo y de navegación por internet. En seguida se ha pasado a la adquisición de habilidades básicas a través del uso del procesador de texto.

En esta primera aproximación a la "máquina" se hicieron evidentes los límites ergonómicos que esta tiene respecto a las personas mayores. El grupo ha presentado una buena disposición a la colaboración, así que las mujeres con particular dificultad a utilizar el ratón o las teclas, sea por problemas de visión o de movimientos, encontraron una compañera dispuesta a desarrollar la tarea conjuntamente. De la misma manera se pudieron apreciar varios aspectos relacionados con el auto concepto que cada mujer tenía de sí misma, dato muy valioso a la hora de llevar a cabo el objetivo principal de los talleres, en cuanto al análisis del cambio, el auto concepto es lo primero que se somete a trasformación a partir de la experiencia formativa.

La inseguridad y la baja autoestima, que las mujeres presentaron en el primer momento, fueron los aspectos que más se han destacado en las primeras sesiones. A lo largo del proceso estas situaciones se han ido desvaneciendo, a medida que el manejo de la máquina les ha resultado más cómodo y familiar.

En particular, al empezar el trabajo de navegación por internet y uso del procesador de texto, las mujeres parecían desorientadas y presentaban muchas dudas en torno a la comprensión y realización de la tarea que se le demandaba. Enfrentarse al uso de un ordenador, herramienta moderna de dominio de las generaciones más jóvenes, les ha supuesto romper completamente las ideas que tenían respecto a sus capacidades. Probablemente estas mujeres habían visto utilizar este instrumento y conocían sus capacidades, pero jamás se habían atrevido a acercarse a él. Debido a esa actitud, se necesitó para la tarea de aprendizaje una gran labor de apoyo, estímulo positivo que reforzara en ellas, la convicción de poder enfrentarse a la tarea que se estaba llevando a cabo.

A partir de la segunda sesión, las dinámicas de trabajo se centraron sobre todo en la práctica y en el uso del ordenador y de la navegación en internet, para que se pudiera desarrollar la temática elegida en los grupos de discusión: La recuperación de la memoria histórica.

La tercera sesión de los talleres se abrió con la recolección de las fotos que se llevaron como muestra del pasado y de las actividades que habían realizado a lo largo de su vida. En un principio, junto a la selección de las fotos traídas se describió la imagen y el contexto de estas. De aquí salieron muchas historias que descubrían lazos comunes entre ellas que, hasta aquel momento, no habían sabido compartirlos.

Hay que destacar la escasez de documentación fotográfica recuperada. Esto probablemente es debido a la falta de recursos que ha caracterizado la vida de las mujeres que han participado en la formación, escasez que no les ha permitido hacer ni tener fotos de su pasado ni de su presente. Esta falta de material fotográfico ha sido sustituida por la redacción de las historias de vida, como testimonio de su memoria. 
Aprovechando las pocas fotos que se han podido recuperar, se ha pasado a la explicación, por parte de las formadoras, del proceso de escaneado y al escaneado de las fotografías por parte de las participantes. Cada una, con la ayuda de las formadoras, ha empezado el tratamiento digital de las fotografías y documentación de estas, mediante el procesador de textos.

A través del esfuerzo de descripción de las fotos y de la redacción de sus memorias se ha conseguido valorizar el rol y las funciones de las mismas protagonistas, compartir experiencias comunes y estimular los recuerdos. El hecho de compartir experiencias, recuerdos $e$ historias, ha creado en clase una dinámica favorable para que se logre el un cambio respecto a su autoconcepto; las mujeres han continuado valorando sus calidades como trabajadoras, esposas y madres, pero no solo para sí mismas, sino que han descubierto lo importante que su rol representa para los demás.

La cuarta sesión fue dedicada a la navegación en internet, para encontrar imágenes $y$ documentos.

En relación al uso del nuevo medio tecnológico, se pudo notar un cambio de actitud respecto a la primera sesión, en cuanto se superaron, en gran parte, las tensiones $e$ incomodidades respecto a la utilización del medio. Ya en la tercera sesión las mujeres parecían tener más confianza, conociendo la terminología, y no les asustaba enchufar la máquina y encontrarse enfrente de la pantalla así como navegar en internet, buscar fotos o historias del municipio o de sus pueblos.

Un aspecto a destacar es la cooperación entre ellas, un fuerte sentido de apoyo mutuo $e$ ironía ante los errores cometidos, que elevó los ánimos y las ganas de aprender en el aula. La quinta y última sesión sirvió para acabar de escanear y tratar el material fotográfico, y para que ellas misma dieran una demostración práctica de la actividad tradicional del municipio. En la mismo sesión se realizaron entrevistas.

\section{Las historias de vida}

El trabajo de recuperación de la memoria a través de la redacción de las historias de vida fue un proceso muy importante para el empoderamiento de las mujeres que participaron en los talleres.

Previamente al ejercicio de escritura se introdujeron los conceptos de patriarcado, perspectiva de género, derechos de las mujeres, historia de las mujeres, conceptos que fueron fundamentales, junto al debate en el grupo, para releer y reinterpretar sus experiencias. En el proceso de escritura se presentó la necesidad de apoyar las beneficiarias del taller en la redacción, en cuanto no todas presentaban un nivel de alfabetización suficiente para tal fin. En esto también se ha podido observar la colaboración y la ayuda que las integrantes del grupo han ofrecido a sus compañeras.

Explicitar las experiencias vividas, las emociones, los retos fue una parte crucial en el proceso de cambio para este grupo de mujeres. Muchas pudieron reconocer las injusticias en determinados actos padecidos, que hasta hacía poco consideraban como simple destino que le tocó vivir. El hecho de compartirlo con el grupo y redactar las historias fue un acto de denuncia frente a un pasado, que para alguna es aún presente, y que fueron capaces de sacarlo a la luz.

El esfuerzo en recordar fue un proceso a veces doloroso pero también ayudó a resaltar la valentía que cada una había empleado en salir adelante. Se pudieron recuperar varias experiencias de mujeres pioneras en su entorno con respecto al trabajo, con respecto al querer salir de los roles cerrados de la familia; mujeres que educaron sus hijas e hijos sin ayuda, que pudieron y pueden enfrentarse solas a muchos obstáculos y que se convierten en ejemplo para muchas de nosotras (ver Anexo 1).

Estas historias nos cuentan la lucha, la resistencia al dolor de las mujeres que han tenido por primera vez la oportunidad de revalorarse a sí mismas a través de la denuncia de su experiencia, hasta ahora guardada con vergüenza en sus recuerdos. 
Somos conscientes de que el proceso de cambio $y$ de empoderamiento no se puede alcanzar en un espacio de tiempo tan limitado como han sido los talleres de alfabetización digital propuestos en el Municipio de Pamplona, no obstante se ha podido observar como la percepción de ellas mismas ha cambiado respecto al primer encuentro, la voluntad y la fuerza de contar lo vivido, con matices de rabia e ironía nos indica un inicio de una nueva perspectiva hacia los acontecimientos de la vida.

\section{La entrevista semidirigida}

Para realizar las entrevistas se pidieron voluntarias como representantes del grupo. La entrevista fue focalizada prevalentemente a evaluar el proceso de formación, respecto al contenido impartido y aprendido, al material entregado, a la temporalización de los talleres y a la infraestructura. Durante la entrevista se procuró crear un ambiente cómodo y relajado, dejando espacio a las entrevistadas para que expresaran sus ideas $y$ opiniones.

En total se han entrevistado 10 mujeres. Lo que se puede destacar en el resultado de las entrevistas es sobre todo el agradecimiento que las mujeres sintieron hacia esta iniciativa de formación. Expresaron la sorpresa de verse capaces de manejar el ordenador, de poder escribir y enviar un mail. Reconocieron la importancia del diálogo y la confrontación sobre temáticas que nunca, hasta esta ocasión, habían tratado en público, y se sorprendieron de cuantas mujeres habían vivido las mismas historias y que se habían quedado calladas.

A lo largo de las entrevistas las mujeres valorizaron su roles y su capacidad, el saber que la grabación hubiera podido salir de las aulas les dio el coraje de reafirmarse delante de la sociedad como mujeres trabajadoras y luchadoras, como mujeres que no se rinden delante de ningún reto, ni siquiera delante el uso del ordenador... Resaltaron la importancia de difusión de este trabajo para que sirviese de estímulo a otras comunidades y a otros grupos $y$ expresaron el deseo de continuidad del proceso pedagógico.

\section{CONCLUSIONES}

Hoy en día es posible, gracias a los avances sociales, tecnológicos e informativos que a todas llegue el mensaje que viene de otras áreas de la sociedad, que informa a las mujeres de la existencia de un macro-proceso de liberación, que está promoviendo un cambio en general en la estructura social y por lo tanto es promotor de nuevas oportunidades y una lenta disminución de la discriminación, que hasta ahora las mujeres han tenido que vivir (Borrel 1999). Esta toma de conciencia ayuda a las mujeres a un proceso abierto y flexible para hacer frente a nuevos discursos, que tratan de preguntas dirigidas a realizar un cambio en la actitud que cada una tiene hacia sus propias capacidades y en relación al cambio social.

Sabemos que todavía falta para que este cambio de actitud se arraigue en la personalidad de estas mujeres; sin embargo, estamos convencidas de que esta experiencia les ha dado para pensar y replantearse posturas y convenciones. Se han sentido valoradas por el grupo y de reflejo han sentido la importancia de su trabajo en la sociedad.

Compartiendo su experiencia se han sentido menos solas, contando sus logros han reforzado su autoestima. Se han atrevido a contar, a denunciar, a reírse de ellas mismas, a llorar, a navegar por la red y así "ver un poquito de mundo" y alguna se ha atrevido también a escribir para nosotras...

\section{AÑORANZAS DEL AYER}

No todas las cosas sucedidas en tu vida han podido ser simples y desagradables, llénate de motivos donde prime la simplicidad y sencillez de todas esas cosas bellas y hermosas que han rodeado tu vida, cosas por las que, por alguna razón, has podido esbozar una sonrisa de satisfacción y alegría.

Es posible que hoy no recuerdes ni venga nada a tu mente, pero espera un momento, no te 
desesperes porque si tu pasado es esquivo a tus recuerdos, aún el mañana queda por vivir.

Añora el pasado con honor y orgullo de lo vivido, sin que esto sea un obstáculo en tu vida para seguir adelante. Tu voluntad no debe estar sujeta a solo caprichos porque estos no permiten que veamos con claridad y lucidez nuestro presente. Este breve escrito es el inicio de lo que significa para mí una añoranza del ayer.

Mi pueblo hermoso y maravilloso enclavado a orillas del río Magdalena cuyas aguas con un mover sensual, silencioso recorren con orgullo sus riveras cada mañana. No hay un mejor atardecer que el de mi pueblo! Qué atardecer! Mis ojos quedan extasiados al mirar como, un poco tímido, se oculta el sol tras las montañas, tornándose brillante y rojizo, es un espectáculo inolvidable digno de una poesía llena de amor y melancolía...

Mi pueblo es como un guerrero que con el paso de los años se hace más fuerte, es una fortaleza que se trasmite a los que en él habitan reflejada en su tesón y alegría

María Paula Pacheco, Pamplona, 2010 


\section{REFERENCIAS}

Aguado, G., Escofet, A. y Rubio M. J. (2009) "Empoderamiento, tecnologías de la información y la comunicación y género. Una aproximación conceptual." Universidad de Barcelona. En de Pablos Ma Elena Jaime "Identidades femeninas en un mundo plural" (Ed.) Colección AUD EM ISBN: 978-84-96980-81-5 c2009 Arcibel editores. pp. 11-18.

Ahumada, C. (2008) "Políticas públicas y condiciones sociales de la mujer en Colombia en el siglo xxi: entre el ajuste fiscal y el conflicto armado" Umbrales. Revista del Postgrado Multidisciplinario en Ciencias del Desarrollo Print ISSN 1994-4543. vol.1 no.18 La Paz Nov.

Ander-Egg, E. (1995) Repensando la Investigación-Acción participativa: Comentarios, Críticas, Sugerencias. México D. F.: El Ateneo, S. A.

Bertaux, D. (1993) De la perspectiva de la historia de vida a la transformación de la práctica sociológica. En "Marinas, J.M. y Santamaría, Cristina ed., "La historia oral: métodos y experiencias". Madrid: Debate.

Blonder, G. (2007) Género, TIC/Sociedad de la Información en Iberoamérica X Conferencia sobre la Mujer de América Latina y el Caribe - CEPAL- Quito, Ecuador - 6 al 9 de agosto 2007Disponible en internet http://www.catunescomujer.org. Consultado el 04 de mayo de 2010.

Borrel, V. (1999) La educación de mujeres adultas, Serie fundamentos $\mathrm{N}^{\circ} 10$, Colección investigación y enseñanza. Díada Editora, Sevilla. pp.: 35-166-177.

Del Prete, A., Calleja, C. y Gisbert Cervera, M. M. (2011)"Overcoming generational segregation in ICTs: Reflections on digital literacy workshop as a method" (pp.159-174) ISSN: 0971-8524. Gender, Technology and Development. Acient Institut technology (AIT) Gender and development studies. SAGE publication. Disponible en internet http://gtd.sagepub.com

Del Prete, A. y Calleja, C. (2011) "Empowering women through a formation training ICT: strategies and methodology to recover women's historical memory in rural areas." 2011. Editorial Assistant for "Education in a technological world: communicating current and emerging research and technological efforts" Formatex Research Center. ISBN (13): 978-84-939843-3-5. http:// www.formatex.org/ict/

Informe Nacional de Competitividad (2012-2013) Ruta a la prosperidad Colectiva. Consejo Privado de competitividad (p.160-177) Disponible en internet http://www.compite.com.co/site/ wpcontent/uploads/2012/11/INC-2012-2013.pdf

Finquelievich, S. y Martínez, S. (2004) "Mujeres en américa latina y el caribe: ¿̇son las tecnologías de información y comunicación un arma efectiva para luchar contra la pobreza? en la Revista venezolana de estudios de la mujer. Caracas: enero-junio, Vol. 9, № 22 pp. 135-137.

Gurumurthy, A. (2004) GENDER and ICTs Overview Report. Institute of Development Studies ISBN 1- $85864-840-8$.

Hafkin, N. y Huyer, S. (2006) Cinderella or Cyberella? : Empowering Women in Knoledge society. Editor Kumarian Press. ISBN-13: 978-1-56549-219-6. 
León, M. de (comp) (1997) Poder y empoderamiento de las mujeres. (pp. 190-195). Bogotá: Coedición del tercer mundo editor.

Meertens, D J. et all., (2007) Colombia: brechas, diversidad e iniciativas. Mujeres e igualdad de género en un país en conflicto. Bogotá: El Malpensante

Ministerio de Protección Social. Política Pública de Salud Sexual y Reproductiva. Disponible en internet http://www.minproteccionsocial.gov.co/

Niño, L. y Núñez, L. (2009) Colombia: violencia contra las mujeres y las tecnologías de información y comunicación ¿Superando el patriarcado? Asociación para el Progreso de las Comunicaciones (APC) Disponible en internet www.colnodo.apc.org/.../colombia_APC_PARM_ODM3_ violenciaytic_informenacl_esp.pdf. Consultado el 03 de agosto de 2010.

Pavón Castellano, A. (2000) El aprendizaje de los Mayores y las Nuevas tecnologías. En Valenzuela, E. y Acala, E. (Eds.): El aprendizaje de las personas mayores ante los retos del nuevo milenio. (pp. 197-236). Madrid: Dykinson.

Rodríguez, G.y Gil Jiménez J. E. (1996) Metodología de la investigación cualitativa. (pp. 34-37). Málaga: Aljibe.

Rostagnol, S. (2003) Organizaciones de mujeres, redes y TIC Centro de Competencia en Comunicación para América Latina. Disponible en internet http://www.c3fes.net. Consultado el 27de agosto de 2010.

Scott Dixon, K. (2000) From webgrrls to digitaleve. The gendered practice of women's technology and organization Tesis Doctoral en Women Studies, Universidad de York, Toronto. Disponible en internet http://www.stumptuous.com. Consultado el 31 de marzo de 2008.

Tom, W. (1989) Effects of feminist research on research methods, Laurier, Toronto, UNESCO: "Hacia las sociedades del conocimiento" Disponible en internet http://portal.unesco.org/culture/ es/. Consultado el 03 de diciembre de 2009.

Valenzuela, E. y Acala, E. (Eds.): El aprendizaje de las personas mayores ante los retos del nuevo milenio. (pp.197-236). Madrid: Dykinson. 


\section{ANEXO}

\section{Extraído del dossier "Historias de vidas de las mujeres de Pamplona" (Pamplona, 2010):}

Testimonio de una mujer de taller de Alfabetización digital (Pamplona, 2010):

"Nosotros vivíamos a 8 leguas del pueblo, nosotros éramos 11 hijos. Mi papá era una persona muy pobre, no tenía nada, vivía en el campo, en San Rafael. Yo me venía todos los jueves con él a pie a la 1 de la mañana, tardábamos 8 horas en llegar a Pamplona, a vender pollos, huevos, marranos, queso y demás cosas que les comprábamos a los vecinos para venderlos en el pueblo y con la ganancia comprábamos el mercado de la semana. Desafortunadamente me casé y me fue mal, tenía 17 años y el tenía 22, obligada y no lo elegí.

Un día se incendió la cocina, él me dio un puño y se me cayeron las muelas y me fui donde una vecina. Mi suegra dijo que todo era mentira. El me quería llevar con él a la casa pero yo tenía miedo porque amenazaba con matarme, me agarré de la puerta y no me dejé entrar para dentro. La gente se reunía a mirar el espectáculo, a el lo alababan y a mi me humillaban. Mis padres no iban a la casa porque le tenían miedo. El me daba correa. Desde que se murió la mamá, no se porta así conmigo, porque sólo me tiene a mí.

Yo tuve sola a todos mis hijos en la casa y sólo dos de ellas en el hospital. Antes de tenerlos me tomaba un café con tres ramas de hierbabuena y botaba una cobija al suelo, me arrodillaba, los tenia y cortaba el ombligo, el cordón que sobraba me lo amarraba de la pierna, me sacaba la placenta, los secaba, los vestía.

Mi vida fue muy dura pero saqué a todos mis hijos adelante, porqué con la ayuda de nuestro padre DIOS y de la VIRGEN MARIA todo se puede. $Y$ en este momento trabajo en escobas $y$ traperos.

Testimonio de una mujer de taller de Alfabetización digital (Pamplona, 2010):
Mi nombre es xxxx, fuimos 15 hermanos, mi mamá trabajaba en casas de familias y lavando ropas a estudiantes. De 15 hermanos quedan 9 vivos, 4 mujeres y 5 hombres, yo soy la mayor. Mi papá fue albañil, él le pegaba a mi mamá. Nosotros cocinábamos con leña y dormíamos en una habitación, mi papá tomaba mucho y llegaba a pegarnos a todos, él tenía muchas mujeres porque decía que para eso son los hombres, mi mamá le tocaba embarazada cargar un bulto de leña a la espalda, porque vivíamos muy pobres y si no trabajaba no teníamos con que comer.

Testimonio de una mujer de taller de Alfabetización digital (Pamplona, 2010):

Cuando era pequeñita me gustaba mucho jugar con el barro y a medida que fui creciendo me gustaba bordar, tejer, cantar y bailar. La música que más me gustaba cantar y bailar: la carranguera.

Mi esposo vendía papas en el centro de acopio, todos los días de la semana desde las 5 de la mañana hasta la 6 de la tarde. El fue un señor muy bueno pero cuando se emborrachaba, o sea cada viernes, era muy grosero y me tocaba irme con mis hijos de la casa para evitar que me pegara y no oír las groserías que me decía. Al día después el me venia a buscar me convencía a ir para la casa y a seguir la misma historia. Me le volé y me vine para Pamplona, el se vino a llevarme pero yo no quise más. Entonces él se vino y siguió el mismo cuento, yo tuve un niño inválido que se murió. Él seguía con la misma historia y entonces yo pensé ćsi no tengo más hijo que cuidar porque tengo que aguantarlo? $Y$ entonces me separé de él, me fui a vivir sola, pagando arriendo y trabajando duro, haciendo aseo en El Museo de Arte Moderno.

Contrariamente a las mujeres de mi generación que aguantaron y siguen aguantando los maridos yo tuve el valor de dejarlo porque yo me valgo por mi misma, yo puedo vivir sin él y mejor. Ahora recién se ha muerto y yo volví a mi casa, sigo trabajando a los 72 años y aún le doy al mundo. 
Yo tuve un problema, mis hijos y mi nieto me los secuestró la guerrilla, los secuestraron un lunes. Luego el viernes, nos engañaron diciéndonos que les iban a llevar a la casa pero en el camino los mataron entre Cácota y Chitagá. Enterramos a mis hijos...

Testimonio de una mujer de taller de Alfabetización digital (Pamplona, 2010):

Mi vida fue muy triste porque no conocí a mi familia. Yo nací en Ragonvalia el 01 de noviembre de 1963. La que me crió fue una profesora y no me dio estudio porque primero eran los oficios, remedios caseros, la leche con merengue para la tos, agua de hierbas para la gripa. Para salir afuera de la puerta había que pedir permiso porque si no, nos pegaban, me maltrataba mucho....

Mi marido ha estado muy bravo conmigo. Nunca me ha pegado pero me insultaba por todo, nada le parecía bien, yo me creía lo que el me decía, en cuanto no tuve ni niñez ni juventud... Tuve un hijo a los 13 años, por una violación, y no le conté nada la señora, pero cuando lo supo me pegó muy duro y me mandó a tenerlo a escondida en Cúcuta, entonces me avisaron de que no volviera a la casa con el niño y me lo hicieron regalar. 